\title{
Deciding Optimal Location of DPFC in Transmission Line Using Artificial Algae Algorithm
}

\author{
Jaydeep Chakravorty \\ Electrical Engineering Department, Indus University \\ Ahmedabad, India
}

\author{
Jyoti Saraswat \\ ALPLA India Pvt. Ltd. \\ Dadra \& Nagar Haveli, India
}

\begin{abstract}
In this paper, the application of artificial algae algorithm (AAA) in optimal placement distributed power flow controller (DPFC) with MCFC in transmission networks has been proposed The proposed method is tested on IEEE 14- bus system and the results are discussed. The biggest advantage of DPFC is that it can control the active and reactive power flow and bus voltages, simultaneously. In this paper, the optimal placement of one DPFC in IEEE-14 bus system and then optimal placement of two DPFCs in IEEE-14 bus system has been proposed. Optimal placement of DPFC in power system by AAA leads to increased stability and capacity of the power transmission in lines. The proposed model has been simulated in Matlab/Simulink and the performance results are tabulated.
\end{abstract}

Keywords-artifical algae algorithm; DPFC; MCFC

\section{INTRODUCTION}

Increase in power demand has led modern power system networks to operate under stressed conditions. Load increase in the system is tolerable up to a particular limit but if it is increased further it may lead to voltage drop which may result to system instability and line overloading. FACTS devices help maintain system stability and maintain the system to normal condition. Many researchers proposed different methods to install FACTS devices in the system [1-5]. Optimal location of various FACTS devices in different test systems was done by multi-objective generalized approach [6], genetic algorithm and DE [7], PSO and harmony search algorithm [8] and several hybridized methods [9-12]. The major role of FACTS is to control the flow of real and reactive power by injecting a voltage in series with the transmission line. Real and reactive power flow control allow power flow in the specified routes. A new DPFC model with MCFC and ultra-capacitor is proposed in [13]. In this paper, AAA has been used to determine the optimal location of the DPFC proposed in [13].

\section{ARTIFICIAL ALGAE ALGORITHM}

It is a bio inspired meta-heuristic algorithm [14]. This algorithm has three main basic parts called evolutionary process, adaptation, and helical movement [15].

\section{A. Evolutionary Process}

In this process, the algae receive sufficient nutrients and enough sunlight to grow and reproduce. But if the circumstances are not supportive, for example if the sunlight is not enough, then the algae may die. This process can be mathematically expressed by:

$$
G_{j}^{t+1}=\left(\frac{f_{j}(x)}{k+f_{j}(x)}\right) \times G_{j}^{t} \quad \text { for } j=1,2,3, \ldots . \mathrm{N}
$$

where, $G$ is the size of the $j$ th algal in time $t$ and $N$ is the colony in the system. Of all $N$ colonies, the colonies that provide better solutions grow bigger because they get enough sunlight to grow. The colonies which do not give good solutions become smaller. The smallest colony dies. $D$ is the problem dimension.

$$
\begin{array}{ll}
\text { colony }^{\text {big }}=\max \left(G_{j}^{t}\right) & \text { for } j=1,2,3, \ldots . N \\
\text { colony }^{\text {small }}=\min \left(G_{j}^{t}\right) & \text { for } j=1,2,3, \ldots . N \\
\text { colony }_{m}^{\text {small }}=\text { colony }_{m}^{\text {big }} & \text { for } m=1,2,3, \ldots . D
\end{array}
$$

\section{B. Adaptation}

In this process the insufficiently grown algal colony tries to adapt to the environment. The insufficiently grown algal colony tries to resemble itself to the biggest algal colony:

$$
\begin{aligned}
& \operatorname{starv}^{t}=\max \left(A_{j}^{t}\right) \quad \text { for } j=1,2,3, \ldots N \\
& \operatorname{starv}^{t+1}=\operatorname{starv}^{t}+\left(\text { colony }^{\text {big }}-\text { starv }^{t}\right) \times \text { rand }
\end{aligned}
$$

The initial starvation value is assumed to be zero for each algal and it is increased with time $t$. The starvation value of the $j$ th algal colony in time $t$ is $A_{j}^{t}$. The algal colony with the highest starvation value in time $t$ is $\operatorname{starv}^{t}$. Ap is a constant in the interval $[0,1]$ called adaptation constant which determines whether adaptation process will be applied or not in time $t$. If rand $>A p$ then the adaptation will be applied.

\section{Helical Movement}

The algal cells generally swim helically to stay close to the water surface. Movement restriction due to gravity is displayed as 0 and viscous drag is displayed as shear force which is proportional to the size of the algal cell.

$$
T\left(x_{j}\right)=2 \pi\left(\sqrt[2 / 3]{\frac{3 G_{j}}{4 \pi}}\right)
$$




$$
\begin{aligned}
& x_{j m}^{t+1}=x_{j m}^{t}+\left(x_{i m}^{t}-x_{j m}^{t}\right) \times\left(\Delta-T\left(x_{j}\right)\right) \times p \\
& x_{j k}^{t+1}=x_{j k}^{t}+\left(x_{i k}^{t}-x_{j k}^{t}\right) \times\left(\Delta-T\left(x_{j}\right)\right) \times \cos \alpha \\
& x_{j l}^{t+1}=x_{j l}^{t}+\left(x_{i l}^{t}-x_{j l}^{t}\right) \times\left(\Delta-T\left(x_{j}\right)\right) \times \sin \beta
\end{aligned}
$$

\section{APPLICATION OF ARTIFICIAL ALGAE ALGORITHM}

The algorithmic steps of the application of AAA in optimal placement of DPFC with PEM are:

1. Randomly select DPFC parameters $V_{s e}$ and $V_{s h}$.

2. Perform load flow analysis of the system.

3. From the obtained result of step 2, calculate the value of the objective function.

4. Select the minimum value of the objective function as the best algae solution.

5. Update the algae colony using helical movement.

6. Perform the operation of reproduction and adaptation.

7. Repeat steps 2-4.

8. Compare the two outputs. If the stopping condition is achieved then stop, else repeat the same process again.

\section{PROBLEM FORMATION}

The proposed algorithm has been tested with standard IEEE 14 bus system. Numerical data and parameters were taken from [16]. In IEEE 14 bus system, load flow analysis is performed using the Newton Raphson method and the ranking is obtained from contingency analysis. The transformer ratio varies from its nominal value during the calculation process. First, the process assumes one DPFC is required to be placed in the system then the process is repeated for two DPFCs.

\section{Simulation AND RESUlTS}

Ranking and performance parameter (PP) of the system based on contingency analysis is given in Table I. In Table I, only transmission lines whose PP is greater than or equal to 1 are shown. Table II, represents the optimized values of the transformer tap ratio. When one DPFC is considered, the application of AAA gives the location of DPFC between bus 4 and bus 10 as shown in Table III. When two DPFCs are considered, the application of AAA gives the location of DPFCs between bus 4 and bus 5 and between bus 6 and bus 9 as shown in Table IV. The final bus voltages after the simulation is over are given in Table $\mathrm{V}$.

TABLE I. RANKING

\begin{tabular}{|c|c|c|c|c|c|c|}
\hline $\begin{array}{c}\text { Line } \\
\text { No. }\end{array}$ & $\begin{array}{c}\text { From } \\
\text { Bus }\end{array}$ & $\begin{array}{c}\text { To } \\
\text { Bus }\end{array}$ & $\begin{array}{c}\text { No. of } \\
\text { overload lines }\end{array}$ & $\begin{array}{c}\text { No. of voltage } \\
\text { violations }\end{array}$ & PP & Rank \\
\hline 1 & 1 & 2 & 5 & 7 & 12 & 1 \\
\hline 3 & 2 & 3 & 4 & 5 & 9 & 2 \\
\hline 2 & 1 & 5 & 2 & 6 & 8 & 3 \\
\hline 10 & 5 & 6 & 1 & 5 & 6 & 4 \\
\hline 4 & 2 & 4 & 2 & 3 & 5 & 5 \\
\hline 14 & 7 & 8 & 0 & 3 & 3 & 6 \\
\hline 15 & 7 & 9 & 1 & 2 & 3 & 7 \\
\hline 13 & 6 & 13 & 1 & 2 & 3 & 8 \\
\hline 5 & 2 & 5 & 0 & 1 & 1 & 9 \\
\hline 7 & 5 & 4 & 0 & 1 & 1 & 10 \\
\hline 9 & 4 & 9 & 0 & 1 & 1 & 11 \\
\hline 20 & 13 & 14 & 0 & 1 & 1 & 12 \\
\hline
\end{tabular}

TABLE II. TRANSFORMER TAP RATIO

\begin{tabular}{|c|c|c|}
\hline From & To & Ratio \\
\hline 3 & 4 & 1.064 \\
\hline 4 & 6 & 1.062 \\
\hline 6 & 8 & 1.042 \\
\hline 9 & 11 & 1.081 \\
\hline 12 & 13 & 1.109 \\
\hline 14 & 15 & 1.084 \\
\hline 16 & 17 & 1.038 \\
\hline 18 & 19 & 1.074 \\
\hline 10 & 21 & 1.052 \\
\hline
\end{tabular}

TABLE III. RESULT WITH ONLY ONE DPFC

\begin{tabular}{|c|c|c|}
\hline Bus No. & Pi & Qi \\
\hline 4 & -200 & -150 \\
\hline 10 & -45 & -20 \\
\hline
\end{tabular}

TABLE IV. RESULT WITH TWO DPFCS

\begin{tabular}{|c|c|c|}
\hline Bus No. & Pi & Qi \\
\hline 4 & -130 & -100 \\
\hline 5 & -200 & -145 \\
\hline 6 & -10 & -3 \\
\hline 9 & -30 & -90 \\
\hline
\end{tabular}

TABLE V. BUS VOLTAGES

\begin{tabular}{|c|c|c|c|}
\hline Bus No. & Without DPFC & With 1 DPFC & With 2 DPFCs \\
\hline 1 & 1.05 & 1.05 & 1.05 \\
\hline 2 & 1.05 & 1.05 & 1.05 \\
\hline 3 & 1.03 & 1.01 & 1.01 \\
\hline 4 & 0.98 & 1.02 & 1.00 \\
\hline 5 & 1.00 & 1.03 & 1.01 \\
\hline 6 & 1.05 & 1.05 & 1.06 \\
\hline 7 & 0.05 & 0.98 & 1.00 \\
\hline 8 & 1.05 & 1.05 & 1.06 \\
\hline 9 & 0.90 & 1.05 & 1.06 \\
\hline 10 & 0.88 & 0.97 & 0.80 \\
\hline 11 & 0.95 & 1.00 & 1.00 \\
\hline 12 & 0.94 & 1.01 & 0.90 \\
\hline 13 & 0.95 & 1.00 & 1.00 \\
\hline 14 & 0.84 & 0.98 & 0.90 \\
\hline
\end{tabular}

\section{CONCLUSION}

In this paper, optimal DPFC placement on an unstable power system because of contingency has been discussed. The optimal location of DPFC in IEEE 14 bus system using AAA has been tested. The proposed algorithm was executed for a maximum of 100 iterations and the results were tabulated. The case study of the IEEE 14-bus system confirmed that the developed algorithm is correct and effective. The losses are reduced and voltage profile is enhanced by placing DPFC(s) at optimal locations. The acquired solutions prove that the AAA has advanced specifications with accurate, balance characteristics, excellent quality of solution and best computation efficiency.

\section{REFERENCES}

[1] S. V. Ravi Kumar, S. S. N. Raju, "Loss Minimization by incorporation of UPFC in Load Flow Studies", International Journal of Electrical and Power Engineering, Vol. 1, No. 3, pp. 321-327, 2007 
[2] A. M. Vural, M. Tumay, "Mathematical modelling and analysis of a unified power flow controller: A comparison of two approaches in power flow studies and effects of UPFC location", Electrical Power and Energy Systems, Vol. 29, pp. 617-629, 2007

[3] B. V. Rao, G. V. N. Kumar, M. R. Priya, P. V. S. Sobhan, "Implementation of Static VAR Compensator for Improvement of Power System Stability", 2009 International Conference on Advances in Computing, Control, and Telecommunication Technologies, Trivandrum, India, December 28-29, 2009

[4] M. D. Reddy, K. D. Babu, "Optimal placement of SVC using fuzzy and PSO algorithm", International Journal of Engineering Research and Applications, Vol. 3, No. 1, pp. 485-490, 2013

[5] V. K. Shende, P. Jagtap, "Optimal Location and sizing of SVC by PSO technique for Voltage Stability Enhancement and Power loss minimization", International journal of Engineering Trends and Technology, Vol. 4, No. 6, pp. 2278-2282, 2013

[6] R. S. Rao, V. S. Rao, "A generalized approach for determination of optimal location and performance analysis of FACTs devices", International Journal of Electrical Power \& Energy Systems, Vol. 73, pp. 711-724, 2015

[7] B. Bhattacharyya, V. K. Gupta, S. Kumar, "UPFC with series and shunt FACTS controllers for the economic operation of a power system", Ain Shams Engineering Journal, Vo. 5, No. 3, pp. 775-787, 2014

[8] N. Karuppiah, V. Malathi, G. Selvalakshmi, "Optimal Placement and Sizing of Multi-type Facts Devices Using PSO and HSA", in: Lecture Notes in Computer Science, Vol. 8947, Springer, 2014

[9] S. Frank I. Steponavice, S. Rebennack, "Optimal power flow: a bibliographic survey II Nondeterministic and hybrid methods", Energy Systems, Vol. 3, No. 3, pp. 259-289, 2012

[10] S. Akumalla, S. Peddakotla, S. R. A. Kuppa, "A Modified Cuckoo Search Algorithm for Improving Voltage Profile and to Diminish Power Losses by Locating Multi-type FACTS Devices", Journal of Control, Automation and Electrical Systems, Vol. 27, No. 1, pp. 93-104, 2016

[11] S. Dutta, P. K. Roy, D. Nandi, "Optimal location of UPFC controller in transmission network using hybrid chemical reaction optimization algorithm", International Journal of Electrical Power \& Energy Systems, Vol. 64, pp. 194-211, 2015

[12] S. A. Taher, M. K. Amooshahi, "New approach for optimal UPFC placement using hybrid immune algorithm in electric power systems", International Journal of Electrical Power \& Energy Systems, Vol. 43, No. 1, pp. 899-909, 2012

[13] J. Chakravorty, J. Saraswat, V. Bhatia, "Modeling a Distributed Power Flow Controller with a PEM Fuel Cell for Power Quality Improvement", Engineering, Technology \& Applied Science Research, Vol. 8, No. 1, pp. $2585-2589,2018$

[14] S. Ali, G. Tezel, E. Yel, "Artificial Algae Algorithm (AAA) for nonlinear global optimization”, Applied Soft Computing, Vol. 31, pp. 153-171, 2015

[15] S. A. Uymaz, G. Tezel, E. Yel, "Artificial Algae Algorithm with multilight source for numerical optimization and application", Biosystems, Vol. 138, pp. 25-38, 2015

[16] M. P. Aghababa, M. E. Akbari, A. M. Shotorbani, "An Efficient Modified Shuffled Frog Leaping Optimization Algorithm”, International Journal of Computer Applications, Vol. 32, pp. 26-30, 2011 